\title{
Effect of fresh soy milk and its compounds on apoptosis in human leukemic cells and peripheral blood mononuclear cells
}

\author{
Qalidah Mohamad Ali ${ }^{1}$, Endang Kumolosasi ${ }^{1 *}$, Mohd Makmor Bakry² \\ ${ }^{1}$ Drug and Herbal Research Centre, ${ }^{2}$ Centre of Quality Management of Medicine, Faculty of Pharmacy, University Kebangsaan \\ Malaysia, Kuala Lumpur, Malaysia
}

*For correspondence: Email: e_kumolosasi@ukm.edu.my; e_kumolosasi@yahoo.co.id; Tel: +60392898054; HP: +60149208598; Fax: +60326983271

Sent for review: 25 April 2020

Revised accepted: 26 February 2021

\begin{abstract}
Purpose: To determine the effect of fresh soy milk and its compounds (coumestrol, daidzein and genistein) on apoptosis in human leukemic cells and peripheral blood mononuclear cells (PBMC).

Methods: The apoptotic effect of fresh soy milk and its compounds on human leukemic cells (K562, Jurkat, U937) and PBMC was determined by flow cytometry. The PBMC from healthy donors were isolated by conducting density gradient centrifugation principle. Lymphoprep and cytotoxicity of the compounds was evaluated by 3-(4,5- '; dimethylthiazol-2-yl)-2,5-diphenyltetrazolium bromide (MTT) MTT) assay.

Results: PBMC treatment of daidzein and genistein had a significantly higher half-maximal inhibitory concentration $\left(I C_{50}\right)$ value $(p<0.01)$ and $(p<0.0001)$, compared to the leukemia cells. In addition, soy milk had a significantly higher IC50 value $(p<0.05)$ in PBMC than the leukemia cells. Coumestrol induced a significantly increased apoptotic cells in K562, U937 cells $(p<0.01)$ and Jurkat cells $(p<$ 0.05). However, daidzein only increased apoptosis $(p<0.05)$ in K562 and U937. Genistein reported a significantly increased apoptotic cell in K562, Jurkat $(p<0.01)$ and U937 cells $(p<0.001)$. Nonetheless, in PBMC, significant apoptosis by the compounds did not occur. However, only soy milk induced a significantly increased apoptosis in PBMC $(p<0.05)$.

Conclusion: The findings indicate that coumestrol, daidzein, genistein and soy milk inhibits the viability of leukemia cells by apoptosis induction, but they are non-toxic toward normal cells. Therefore, the results suggest that the compound alone, and thus, soy milk might have a therapeutic effect in leukemia.
\end{abstract}

Keyword: Fresh soy milk, Phytoestrogen, Apoptosis, Human leukemic cells, Peripheral blood mononuclear cell

This is an Open Access article that uses a fund-ing model which does not charge readers or their institutions for access and distributed under the terms of the Creative Commons Attribution License (http://creativecommons.org/licenses/by/4.0) and the Budapest Open Access Initiative (http://www.budapestopenaccessinitiative.org/read), which permit unrestricted use, distribution, and reproduction in any medium, provided the original work is properly credited.

Tropical Journal of Pharmaceutical Research is indexed by Science Citation Index (SciSearch), Scopus, International Pharmaceutical Abstract, Chemical Abstracts, Embase, Index Copernicus, EBSCO, African Index Medicus, JournalSeek, Journal Citation Reports/Science Edition, Directory of Open Access Journals (DOAJ), African Journal Online, Bioline International, Open-J-Gate and Pharmacy Abstracts

\section{INTRODUCTION}

Leukemia is a type of blood cancer that occurs in adults and children, and characterized as an abnormal growth of white blood cells in the bone marrow. According to the Global Cancer Statistics of 2018 , leukemia represented 437,033 $(2.4 \%)$ new cases and $309,006(3.2 \%)$ deaths, and thus, was ranked $15^{\text {th }}$ place from all 36 cancer sites [1]. This hematogenic disease is 
caused by genetic changes in the normal stem cells, which causes an alteration in the normal cell division and an uncontrolled multiplication of immature leukemia cells [2]. Phytoestrogens are divided into three major groups, which are isoflavone (daidzein, genistein, formononetin, glycetein, biochanin A), coumestans (coumestrol, plicadin, wedelolactone), and lignin which consists of plant lignans and enterolignans [3]. These plant dietary estrogens are mainly found in soy products, nuts, legumes, flax seed oil and cereals [4]. Phytoestrogens are believed to be involved in the prevention and inhibition of cancer cell growth, such as bladder, breast, colorectal and prostate cancers, by having similar structures as estrogen and the potential to bind with the estrogen receptor. For example, consumption of soy milk product is linked to reduced cancer risk [5].

Major components of isoflavones are daidzein and genistein, which are widely found in soybeans, and can suppress the growth and division of cancer cells [6]. Therefore, constituents of soybeans have been widely studied for anticancer properties. Fermented fresh soy milk was shown to induce apoptosis and suppress chemically induced mammary cancer in vivo. In addition, the risk of getting breast cancer in pre menopause and post menopause Asian women were reduced after prior exposure to soy-based products, hence the association of the anticancer properties of soy milk in lessening the risk of getting cancer [7].

Apoptosis is normally known as a programmed cell death, which usually occurs to preserve homeostasis, growth of embryonic, and division of lymphoid and hematopoietic cells [8] . As a regulated programmed cell death, apoptosis occurs by intrinsic and extrinsic pathways that cause some alterations, such as the bulge of a membrane, chromatin rupture and mitochondria impairment [9]. In the extrinsic pathway, activation of a specific ligand, such as tumor necrosis factor related apoptosis inducing ligand (TRAIL), initiates caspase-8 and subsequently activates caspase-3, causing permanent biological and morphological changes. Meanwhile, the intrinsic pathway is stimulated by mitochondria dysfunction and impairment of plasma membrane, which causes permeability and the release of certain proteins such as Cytochrome C through supramolecular pore, thus activating caspase- 9 [10]. Therefore, the purpose of the current study is to determine the effect of fresh soy milk and its compounds on apoptosis in human leukemic cells and peripheral blood mononuclear cells.

\section{EXPERIMENTAL}

\section{Materials}

Coumestrol was purchased from Carbosynhth, China, while daidzein and genistein were purchased from ChromaDex, Los Angeles. The compounds were dissolved in $0.1 \%$ dimethyl sulfoxide (DMSO) purchased from Merck, Germany, to obtain the stock solutions. Fresh Soy Milk was prepared by soaking washed soybeans in distilled water for $10 \mathrm{~h}$, and then the beans were drained, rinsed and blended with distilled water. The blended soybeans were cloth-filtered and pressed into a beaker. The obtained fresh soy milk was boiled for $30 \mathrm{~min}$ and stored in a fridge at $4{ }^{\circ} \mathrm{C}$. It was considered as $100 \%$ fresh soy milk (Unpublished paper).

The compound concentrations used in the assays were obtained from the stock solutions, and diluted with complete media. Acute lymphocytic leukemia (Jurkat) and acute myelogenous leukemia (U937), along with chronic myelogenous leukemia (K562) cell lines were purchased from the American Type Culture Collection (ATCC, USA). The Jurkat and U937 cell lines were cultured in RPMI-160 (Gibco, USA), and K562 cell line in Iscove's Modified Dulbecco's Medium IMDM, (Gibco, USA), which contained penicillin, streptomycin $(100 \mathrm{U} / \mathrm{ml})$, and $10 \%$ fetal bovine serum (FBS). BD Pharmingen ${ }^{\mathrm{TM}}$ Annexin V-FITC was obtained from BD Bioscience, USA. Propidium lodide, (PI), methylthiazolytetrazolium, and MTT were obtained from Sigma, USA, while Hydroquinone was from Merck, Germany.

\section{Purification of peripheral blood mononuclear cells (PBMCs)}

Blood was taken from healthy participant who volunteered to participate in the study and fulfilled the required criteria: aged between 18 and 50 years old, a non-smoker who did not take any supplements or medication, and had fasted overnight. A consent form was gained from each donor before blood collection. This study procedures received approval from the UKM Human Ethical Committee (approval no. UKM.PPI.800-1/1/5/JEP-2019-383) and aligned with principles outlined by the Helsinki Declaration [11].

Blood was collected in EDTA tubes and diluted with the equal amount of plain RPMI-1640 media in 1:1 ratio. The diluted sample was slowly layered above density gradient medium LymphoprepTM (Axis-Shield, Norway), and further centrifuged by using density gradient 
centrifugation at $600 \mathrm{x} \mathrm{g}$ for $20 \mathrm{~min}$ at $20^{\circ} \mathrm{C}$ PBMC layer was slowly removed, washed twice and re-suspended in RPMI-1640.

\section{Cell viability assay}

To determine the viability of cells, MTT assay was carried out as stated by established protocol. Cells at a density of $2 \times 10^{5}$ cells $/ \mathrm{mL}$ were seeded with different compound concentrations (coumestrol, daidzein and genistein) that ranged from $320 \mu \mathrm{g} / \mathrm{mL}$ to 20 $\mu \mathrm{g} / \mathrm{mL}$, and hydroquinone from concentrations of $125 \mu \mathrm{M}$ to $7.8 \mu \mathrm{M}$. Stock of fresh soy milk was diluted from the $100 \%$ stock to $6.25 \%$, then incubated at $37^{\circ} \mathrm{C}$ for $48 \mathrm{~h}$. After incubation, 5 $\mathrm{mg} / \mathrm{mL}$ of MTT was added into each well. Then, DMSO was further added to dissolve the insoluble purple formazan. Absorbance was measured at $570 \mathrm{~nm}$ by using a microtiter plate reader. Cell viability $(\mathrm{V})$ was calculated by using Equation 1.

$V(\%)=\left\{\left(A_{S}-A_{Q}\right) E\left(A_{Q}-A_{Q}\right)\right\} 100$

where, $A_{s}=$ absorbance sample; $A_{-}=$ absorbance of of test control; $A_{b}=$ absorbance blank.

\section{Determination of apoptosis}

PBMC, K562, Jurkat and U937 cells were seeded at a cell density of $5 \times 10^{5}$ cells $/ \mathrm{mL}$, and incubated with coumestrol, daidzein, and genistein at $40 \mu \mathrm{g} / \mathrm{mL}$ concentration, fresh soy milk at $12.5 \%$ concentration, and hydroquinone at $40 \mu \mathrm{M}$ concentration respectively, at $37^{\circ} \mathrm{C}$ for $48 \mathrm{~h}$. The concentrations were chosen based on MTT assay, which gave more than $50 \%$ of viable cells. Cells were cleansed twice with chilled PBS and mixed with Annexin $V$ binding buffer. Propidium lodide and AnnexinV- FITC was included in the suspension prior to analysis by using a flow cytometer (BD FacsCanto II, CA, USA).

\section{Statistical analysis}

All data was expressed as mean \pm standard error mean (SEM), and analyzed by using one-way ANOVA, followed by Bonferroni's post hoc via the GraphPad Prism 5 software and $p<0.05$ was considered statistically significant.

\section{RESULTS}

\section{Cell viability}

The viability of cells after treatment with $40 \mu \mathrm{g} / \mathrm{mL}$ compounds showed more than $50 \%$ viability in most cells. In Figure 1A, coumestrol caused a significantly lower viability of K562 (74.33\% \pm $4.49 \%, p<0.01)$, Jurkat $(68.33 \pm 7.22 \%, p<0.05)$, U937 (52.33 $\pm 2.33 \%, p<0.0001)$, and PBMC $(92.66 \pm 2.18 \%, p<0.05)$ compared to the negative control. Daidzein in Figure $1 \mathrm{~B}$, only showed a significantly lowered viability in $\mathrm{K} 562$ $(67.33 \pm 9.9 \%, p<0.05)$, Jurkat $(60.33 \pm 5.04 \%$. $p<0.01)$ and PBMC (71.66 $\pm 1.66 \%, p<0.001)$. In Figure $2 \mathrm{~A}$, genistein also caused a significantly lower viability in K562 (65 $\pm 4.36 \%, p<0.01)$, Jurkat (49.33 $\pm 8.65 \%, p<0.01)$, U937 (31 \pm $1.73 \%, p<0.0001)$ and PBMC $(74.67 \pm 2.33 \%$, $p<0.0001)$.

Meanwhile, fresh soy milk at concentration of $12.5 \%$ in Figure $2 \mathrm{~B}$, only caused a significantly lower viability in K562 (79 $\pm 7 \%, p<0.05)$, Jurkat $(53 \pm 6.5 \%, p<0.01)$ and U937 (50.67 $\pm 1.43 \%$, $p<0.0001$ ), except for PBMC which reported no significant changes.

Coumestrol, genistein and fresh soy milk showed the highest killing effect toward U937, which was the most sensitive, followed by Jurkat. K562 was the most resistant while daidzein demonstrated less inhibitory effect toward U937, except for K562 and Jurkat. Therefore, coumestrol, daidzein, genistein at concentration of $40 \mu \mathrm{g} / \mathrm{mL}$, and fresh soy milk at concentration of $12.5 \%$ inhibited leukemia cells in a dose dependent manner, except for coumestrol and soy milk in PBMC.

Table 1: $\mathrm{IC}_{50}$ of phytoestrogen and fresh soy milk

\begin{tabular}{lcc}
\hline Compound & Cell type & IC $_{50}(\boldsymbol{\mu M})$ \\
\hline Coumestrol & K562 & $7.19 \pm 0.07$ \\
& Jurkat & $7.64 \pm 0.05$ \\
& U937 & $6.80 \pm 0.10$ \\
Daidzein & PBMC & ND \\
& K562 & $6.88 \pm 0.08$ \\
& Jurkat & ND \\
& U937 & ND \\
& PBMC & $492 \pm 17.08^{* *}$ \\
Genistein & K562 & $6.24 \pm 0.05$ \\
& Jurkat & $5.80 \pm 0.08$ \\
& U937 & $5.18 \pm 0.03$ \\
Fresh soy & PBMC & $551 \pm 6.505^{* * * *}$ \\
milk & K562 & $27.67 \pm 9.28$ \\
& Jurkat & $28.48 \pm 6.49$ \\
& U937 & $19.62 \pm 2.65$ \\
& PBMC & $59.00 \pm 0.57$
\end{tabular}

Note: The concentration of compounds are presented in $\mu \mathrm{M}$,' except for fresh soy milk which is a percentage of soy bean. *, ${ }^{* *},{ }^{* * * *}$ : significant difference with $p<0.05, p<0.01, p<0.0001$ compared with leukemic cells of which their $\mathrm{IC}_{50}$ can be determined; $\mathrm{ND}=$ not determined 

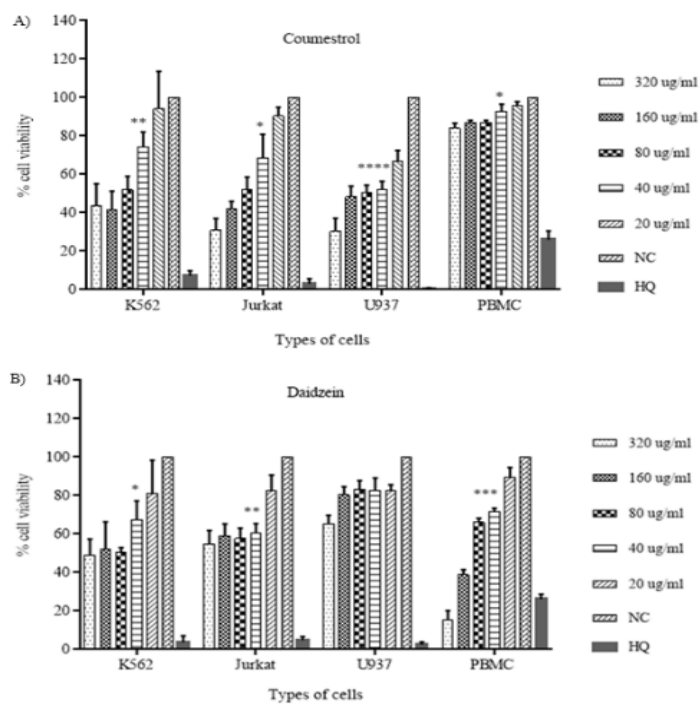

Figure 1: Effect of $(A)$ Coumestrol (B) Daidzein at concentrations of $20 \mu \mathrm{g} / \mathrm{ml}$ to $320 \mu \mathrm{g} / \mathrm{ml}$ on viability of K562, Jurkat, U937 and PBMC cells. Data are presented as mean \pm standard error mean (SEM); $\mathrm{n}=$ 3. ${ }^{* * *} p<0.0001,{ }^{* * *} p<0.001,{ }^{* *} p<0.01$ and ${ }^{*} p<0.05$, significant difference, compared to negative control (untreated cells). Positive control was $40 \mu \mathrm{M} / \mathrm{ml}$ hydroquinone
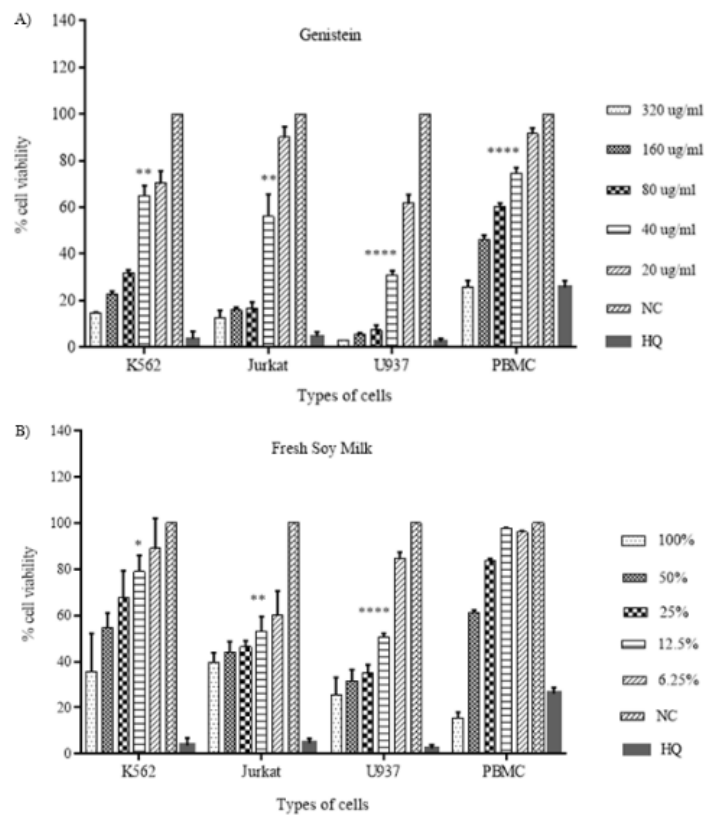

Figure 2: Effect of (A) Genistein at concentrations of $20 \mu \mathrm{g} / \mathrm{ml}$ to $320 \mu \mathrm{g} / \mathrm{ml}$ (B) Fresh soy milk at concentrations of $6.25 \%$ to $100 \%$ on viability of $\mathrm{K} 562$, Jurkat, U937 and PBMC cells. Data was represented as mean \pm standard error mean (SEM) for $n=3$ experiments. ${ }^{* * * *} p<0.0001,{ }^{* * *} p<0.001,{ }^{* *} p<0.01$, ${ }^{*} p<0.05$ significant difference as compared to negative control (untreated cells). Positive control is $40 \mu \mathrm{M} / \mathrm{ml}$ hydroquinone
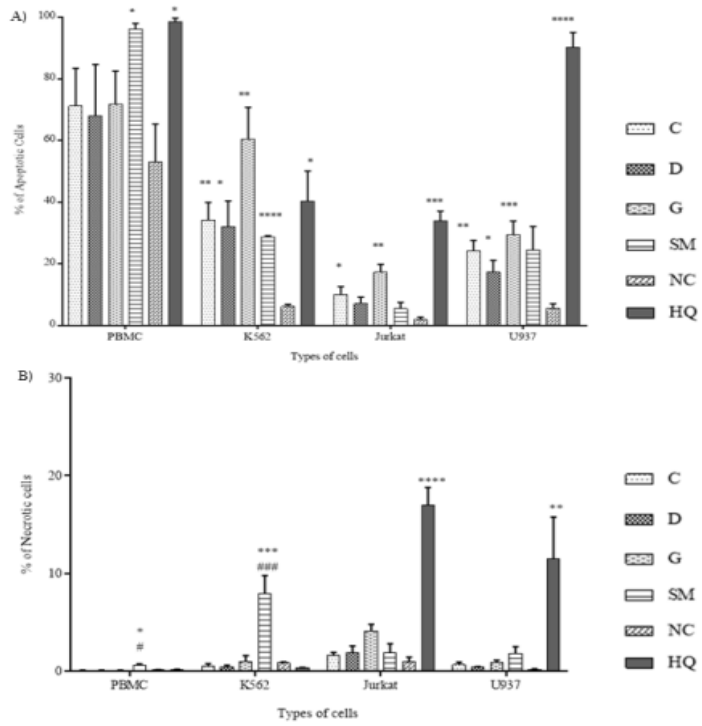

Figure 3: (A) Percentage of apoptosis induced by compounds (B) Percentage of necrosis induced by compounds. The effect was after $48 \mathrm{~h}$ treatment with $40 \mu \mathrm{g} / \mathrm{mL}$ concentration of each compound, $12.5 \%$ concentration of fresh soy milk and $40 \mu \mathrm{M}$ concentration of hydroquinone as the positive control. C: coumestrol, D: daidzein, G: genistein, SM: soy milk, NC: Negative control, HQ: Positive control (hydroquinone). Data were represented as mean \pm standard error of the mean (SEM) for $n=3$ experiments. $\quad{ }^{* * * *} p<0.0001, \quad{ }^{* * *} p<0.001, \quad{ }^{* *} p<0.01$, ${ }^{*} p<0.05$ significant difference compared to the negative control and ${ }^{\# \#} p<0.001,{ }^{\#} p<0.01,{ }^{\#} p<0.05$ significant difference compared to the positive control
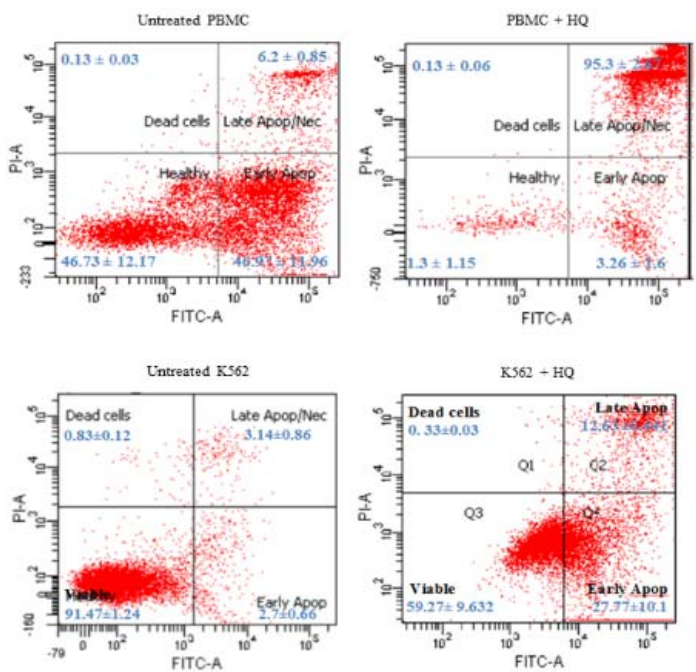

Figure 4: Dot plots of forward- angle light scatter (FSC) vs. side-angle light scatter (SSC) of PBMC and K562 cell as representative cells negative control (untreated cell) and treated positive control (hydroquinone, HQ). Dot plot were divided into four quadrants, which were Q1 (necrotic/ dead cells), Q2 (late apoptotic), Q3 (healthy/viable), Q4 (early apoptotic) 
PBMC + Coumestrol
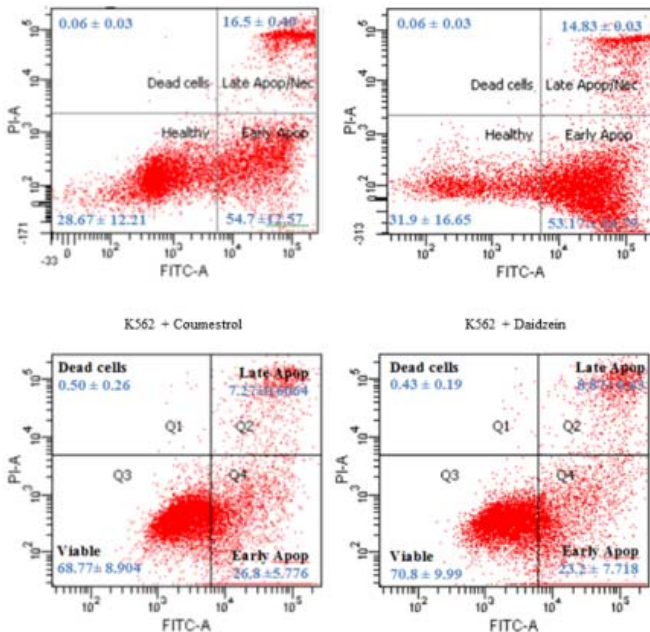

Figure 5: Dot plots of forward- angle light scatter (FSC) vs. side-angle light scatter (SSC) of PBMC and K562 cell as representative cells treated with coumestrol and daidzein. Dot plot were divided into four quadrants, which were Q1 (necrotic/ dead cells), Q2 (late apoptotic), Q3 (healthy/viable), Q4 (early apoptotic)
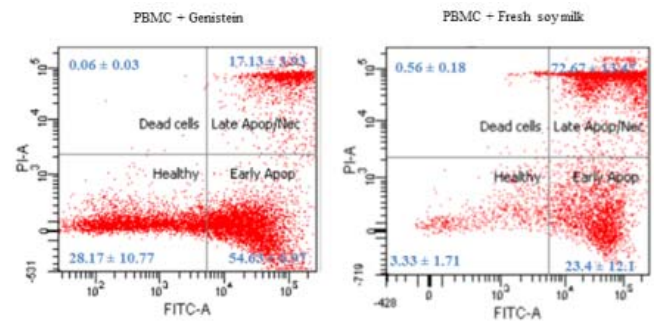

KS62 + Genistein
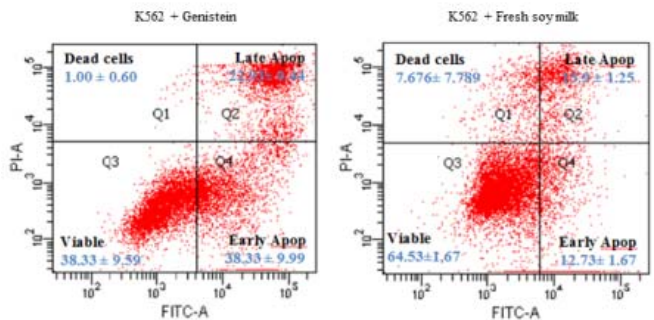

Figure 6: Dot plots of forward- angle light scatter (FSC) vs. side-angle light scatter (SSC) of PBMC and K562 cell as representative cells treated with genistein and fresh soy milk.Dot plot were divided into four quadrants, which were Q1 (necrotic/ dead cells), Q2 (late apoptotic), Q3 (healthy/viable), Q4 (early apoptotic)

\section{Apoptotic and necrotic effects of fresh soy milk and its compounds}

Apoptosis and necrosis are parts of the mechanism for cell death. The result in Figure 3A shows that treatment with compounds caused increased apoptosis of leukemia cells compared to untreated cells. Coumestrol induced apoptosis significantly in K562 (34.07 \pm 5.85) and U937
$(24.28 \pm 3.35 \%)$ with $(p<0.01$,$) while Jurkat (9.97$ $\pm 2.64 \%, \quad p<0.05)$. Genistein significantly increased apoptosis in K562 (60.37 $\pm 10.4 \%)$ and Jurkat $(17.3 \pm 2.54)$ with $(p<0.01)$, while in U937 $(29.3 \pm 4.50, p<0.001)$ in comparison to the negative control. Meanwhile, daidzein only caused significantly increased apoptosis in K562 $(32.07 \pm 8.31 \%)$, and U937 (17.3 $\pm 3.86 \%)$ with $(p<0.05)$. Fresh soy milk showed a_significantly increased apoptosis only in K562 (28.63 \pm $0.46 \%, p<0.0001)$ and PBMC $(p<0.05)$ compared to untreated control. However, soy milk showed a comparable effect with positive control in PBMC, perhaps due to all the tested compounds contained in soy milk. In Figure 3B, percentages of necrotic cells were significantly higher only in fresh soy milk treated K562 $(7.93 \%, p<0.01)$ and PBMC $(0.53 \%, p<0.001)$.

\section{DISCUSSION}

High prevalence of leukemia still showed poor treatment outcome, and thus novel therapeutic agents with less toxicity as compared to chemotherapy drugs are crucially needed [12]. The cytotoxicity effect of soy milk and its compounds were determined based on minimum concentration, which gave $50 \%$ of cell viability. For drugs and pure compounds, $\mathrm{IC}_{50}$ value of less than $4 \mu \mathrm{g} / \mathrm{mL}$ was considered as a cytotoxic compound [13, 14]. The study revealed that coumestrol, daidzein and genistein had $\mathrm{IC}_{50}$ value of slightly higher than $4 \mu \mathrm{g} / \mathrm{ml}$ in all leukemia cells and much higher than $>100 \mu \mathrm{g} / \mathrm{mL}$ toward PBMC, and were significantly different between both types of cells (leukemic cells and PBMC). Although, Soy milk showed $\mathrm{IC}_{50}$ value < $100 \mu \mathrm{g} / \mathrm{mL}$ in human PBMC, the value still had significant difference compared to leukemic cells. Therefore, the study revealed that the tested compounds and soy milk were non-toxic for normal cells at tested concentrations.

In inducing apoptosis, the phytoestrogen compounds induced apoptosis significantly in all leukemic cells tested, except daidzein in Jurkat cells, and they did not cause apoptosis in PBMC. This result suggested that phytoestrogen compounds had strong killing effect toward leukemic cells and may be safe for normal cells, since higher percentage of apoptosis was possibly contributed to by a characteristic of cancer cells, which was more sensitive to the phytoestrogens as compared to normal cells. These results were in line with a previous study, where the same phytoestrogens induced apoptosis and cell cycle arrest in Annexin A1 (ANXA1)-knockdown leukemia cells [15]. Sabran et al reported that ANXA1 level was higher in leukemic cells compared to PBMC [16]. 
Furthermore, when ANXA1 in leukemic cells was knocked down, the cells exhibited apoptosis. Thus, phytoestrogen induced apoptosis might be mediated by ANXA1 [15]. These results were reinforced by Pignata et al, in which the study stated that apoptosis in normal cells might be due to a lengthy incubation period that could stimulate activation of cell death via initiation of mature T cells [17].

Induction of apoptosis in K562 by soy milk was aligned with other studies which successful inhibited the prostate cancer cells growth[18]. Unfortunately, unlike the pure compounds, soy milk in the study induced apoptosis in PBMC. This could be because soy milk is rich in isoflavones, and may induce apoptosis unselectively. The present toxicity effect of coumestrol, daidzein and genistein to cancer cells was in good agreement with some previous studies which satisfactorily showed that high potential of phytoestrogens in killing cancer cells by the induction of apoptosis in prostate, hepatocellular carcinoma, bladder and colon cancer with various mechanism actions involved [19-22]. Anti-estrogenic properties of phytoestrogens will activate estrogen responsive gene to initiate suppression of growth and induced apoptosis via estrogenic receptors (ER) [7]. Moreover, a study of Roma and Spagnuolo (2020) stated that estradiol (E2) improved human-derived pluripotent stem cells (hPSCs) differentiation in an ERa-dependent pathway but was not for ERß. Both ERs are showed in $B$ cells, $\mathrm{T}$ cells, NK cells, dendritic cells, erythrocytes and megakaryocytes, proposing a possible role for ERs in modulating these cell types. The same authors also stated that genistein, one of the phytoestrogens tested in this study, interrelates with both ERa and ER but was reported to have a greater affinity for ER $\beta$. Genistein demonstrates anticancer effects in breast, colon, lung, liver and stomach cancer models in vitro and in vivo, where it targets ERs, several tyrosine kinases and pro-apoptotic factors [23]._In this study, the results suggested that coumestrol, daidzein, genistein and fresh soy milk have therapeutic effects in leukemia treatment, and save the human normal cells.

\section{CONCLUSION}

The findings indicate that coumestrol, daidzein, genistein and soy milk inhibits the viability of leukemia cells by induction of apoptosis, but are non-toxic towards normal cells. Therefore, the result suggested that any of individual compounds and soy milk may exert a therapeutic effect in leukemia.

\section{DECLARATIONS}

\section{Acknowledgement}

This study was funded by the Ministry of Higher Education for Fundamental Research Grant Scheme (FRGS, no. FRGS/1/2018/SKK09/UKM/ 02/2).

\section{Conflict of interest}

The authors declared that there is no conflict of interest associated with this work.

\section{Contribution of authors}

We declare that this work was done by the authors of this article, and all liabilities pertaining to claims relating to its content will be borne by the authors. Endang Kumolosasi and Mohd Makmor Bakry were involved in the experimental design. Qalidah Mohamad Ali conducted the experiments, collected data and analyzed same under the supervision of Endang Kumolosasi and Mohd Makmor Bakry. The manuscript was drafted by Qalidah Mohamad Ali, and finalized by Endang Kumolosasi. All authors have read and approved the final manuscript.

\section{Open Access}

This is an Open Access article that uses a funding model which does not charge readers or their institutions for access and distributed under the terms of the Creative Commons Attribution License (http://creativecommons.org/licenses/by/ 4.0) and the Budapest Open Access Initiative (http://www.budapestopenaccessinitiative.org/rea d), which permit unrestricted use, distribution, and reproduction in any medium, provided the original work is properly credited.

\section{REFERENCES}

1. Bray F, Ferlay J, Soerjomataram I, Siegel RL, Torre LA, Jemal A. Global cancer statistics 2018: GLOBOCAN estimates of incidence and mortality worldwide for 36 cancers in 185 countries. CA Cancer J Clin 2018; 68(6): 394-424.

2. Kumar CC. Genetic abnormalities and challenges in the treatment of acute myeloid leukemia. Genes Cancer 2011; 2(2): 95-107.

3. Viggiani MT, Polimeno L, Di Leo A, Barone $M$. Phytoestrogens: Dietary Intake, Bioavailability, and Protective Mechanisms against Colorectal Neoproliferative Lesions. Nutrients 2019; 11(8): 1709.

4. Cardenas-Trowers O, Meyer I, Markland AD, Richter HE, Addis I. A Review of Phytoestrogens and Their Trop J Pharm Res, March 2021; 20(3): 516 
Association With Pelvic Floor Conditions. Female Pelvic Med Reconstr Surg 2018; 24(3): 193-202.

5. Seo HS, Choi HS, Choi HS, Choi YK, Um JY, Choi I, Shin YC, Ko SG. Phytoestrogens induce apoptosis via extrinsic pathway, inhibiting nuclear factor-kappaB signaling in HER2-overexpressing breast cancer cells. Anticancer Res 2011; 31(10): 3301-3313.

6. Liu J, et al. The associations between plasma phytoestrogens concentration and metabolic syndrome risks in Chinese population. PLoS One 2018; 13(3): e0194639-e0194639.

7. Obiorah IE, Fan P, Jordan VC. Breast cancer cell apoptosis with phytoestrogens is dependent on an estrogen-deprived state. Cancer Prev Res (Phila) 2014; 7(9): 939-949.

8. Testa U, Riccioni R. Deregulation of apoptosis in acute myeloid leukemia. Haematologica 2007; 92(1): 81-94.

9. Samudio I, Konopleva $M$, Carter B, Andreeff $M$. Apoptosis in leukemias: regulation and therapeutic targeting. Cancer Treat Res 2010; 145: 197-217.

10. Loreto $C$, et al. The role of intrinsic pathway in apoptosis activation and progression in Peyronie's disease. Biomed Res Int 2014; 2014: 616149.

11. World Medical Association. Ethic Unit. Declaration of Helsinki 2008. Available from: https://www.wma. net/what-we-do/medical-ethics/declaration-of-helsinki/.

12. Visani G, et al. Low-dose lenalidomide plus cytarabine in very elderly, unfit acute myeloid leukemia patients: Final result of a phase II study. Leuk Res 2017; 62: 77-83.

13. Lee CC, Houghton P. Cytotoxicity of plants from Malaysia and Thailand used traditionally to treat cancer. J Ethnopharmacol 2005; 100(3): 237-243.

14. Pezzuto JM. Book Review Natural Compounds in Cancer Therapy. John Boik, Oregon Medical Press, Princeton, MN, 2001, \$32.00 (ISBN 0-9648280-1-4). Pharm Biol 2002; 40(1): 79-79.

15. Hasan M, Kumolosasi E, Jasamai M, Jamal JA, Azmi N, Rajab NF. Evaluation of phytoestrogens in inducing cell death mediated by decreasing Annexin A1 in Annexin A1-knockdown leukemia cells. DARU J Pharm Sci 2020; 28(1): 97-108.

16. Sabran A, Kumolosasi E, Jantan I. Effects of annexin A1 on apoptosis and cell cycle arrest in human leukemic cell lines. Acta Pharm 2019; 69(1): 75-86.

17. Pignata C, Fiore $M$, de Filippo S, Cavalcanti $M$, Gaetaniello L, Scotese I. Apoptosis as a mechanism of peripheral blood mononuclear cell death after measles and varicella-zoster virus infections in children. Pediatr Res 1998; 43(1): 77-83.

18. Kang NH, Shin HC, Oh S, Lee KH, Lee YB, Choi KC. Soy milk digestion extract inhibits progression of prostate cancer cell growth via regulation of prostate cancer-specific antigen and cell cycle-regulatory genes in human LNCaP cancer cells. Mol Med Rep 2016; 14(2): 1809-1816.

19. Lim W, Jeong M, Bazer FW, Song G. Coumestrol Inhibits Proliferation and Migration of Prostate Cancer Cells by Regulating AKT, ERK1/2, and JNK MAPK Cell Signaling Cascades. J Cell Physiol 2017; 232(4): 862-871.

20. Zheng W, Liu T, Sun R, Yang L, An R, Xue Y. Daidzein induces choriocarcinoma cell apoptosis in a dosedependent manner via the mitochondrial apoptotic pathway. Mol Med Rep 2018; 17(4): 6093-6099.

21. Zhou P, Wang C, Hu Z, Chen W, Qi W, Li A. Genistein induces apoptosis of colon cancer cells by reversal of epithelial-to-mesenchymal via a Notch1/NF-kB/slug/Ecadherin pathway. BMC Cancer 2017; 17(1): 813-813.

22. Shim HY, Park JH, Paik HD, Nah SY, Kim DS, Han YS. Genistein-induced apoptosis of human breast cancer MCF-7 cells involves calpain-caspase and apoptosis signaling kinase 1-p38 mitogen-activated protein kinase activation cascades. Anticancer Drugs 2007; 18(6): 649657.

23. Roma A, Spagnuolo PA. Estrogen Receptors Alpha and Beta in Acute Myeloid Leukemia. Cancers (Basel) 2020; 12(4): 907. 